EGU2020-2205

https://doi.org/10.5194/egusphere-egu2020-2205

EGU General Assembly 2020

(c) Author(s) 2020. This work is distributed under

the Creative Commons Attribution 4.0 License.

\title{
Assessment of PCB trajectories along French river corridors between 1945 and 2018
}

André-Marie Dendievel ${ }^{1}$, Brice Mourier ${ }^{1}$, Alexandra Coynel $^{2}$, Olivier Evrard ${ }^{3}$, Pierre Labadie ${ }^{2}$, Sophie Ayrault ${ }^{3}$, Maxime Debret ${ }^{4}$, Quentin Faivre ${ }^{5}$, Thomas Gardes ${ }^{4}$, Sophia Vauclin ${ }^{1}$, Hélène Budzinski ${ }^{2}$, Cécile Grosbois ${ }^{5}$, Marc Desmet ${ }^{5}$, and Thierry Winiarski ${ }^{1}$

'Univ. Lyon, UMR CNRS 5023 LEHNA-IPE, ENTPE, Vaulx-en-Velin, France (andre-marie.dendievel@entpe.fr)

${ }^{2}$ University of Bordeaux, UMR CNRS 5805 EPOC, Bordeaux, France

${ }^{3}$ Institute Pierre Simon Laplace, UMR CNRS 8212 LSCE, Gif-sur-Yvette, France

${ }^{4}$ University Rouen Normandie, UMR CNRS 6143 M2C, Mont-Saint-Aignan, France

${ }^{5}$ University of Tours, EA 6293 GEHCO, Tours, France

The reconstruction and modelling of contamination trajectories in rivers is a key concern to investigate spatio-temporal impacts of long-term anthropogenic activities. This issue is highly significant for persistent organic pollutants, such as polychlorinated biphenyls (PCBs), known for their toxicity, their low degradation rates and their hydrophobic properties leading to their accumulation in sediments and biota. Increasingly produced and released worldwide from the 1930 s to the 1970-1980s, PCBs were analysed in numerous studies dealing with river sediment quality. However, data syntheses are uncommon at the scale of large hydrosystems, and source-toestuary approaches along rivers are still needed. Accordingly, we propose an original work integrating PCBs analyses on different solid matrices (sediment cores, bed and flood deposits, suspended particulate matters, and dredged sediments) originating from both research programmes and monitoring. Based on more than 1400 validated analyses, temporal trends of the PCB contamination were reconstructed since 1945 along the four main fluvial corridors in France (Rhône, Seine, Loire and Garonne Rivers). The relationships with socio-environmental factors were also deciphered by integrating hydrological and human spatio-temporal data (cumulative river discharge, population hot spots, urban and industrial surfaces). This work highlighted that the main contaminant trends were driven by regulation, but also by sediment transport and accidental releases (especially since the 1990s). In general, urban and industrial areas were the main contributors to the PCB contamination of rivers: around and downstream of Paris and Rouen (Seine River), Lyon and its "Chemical Valley" (Rhône River), Saint-Etienne and Nantes conurbations (Loire River), and probably downstream of Toulouse and Bordeaux (Garonne River). Relatively high concentrations persisted after the end of the PCB production due to chronic diffuse inputs and accidental releases, particularly on the Rhône River. Moreover, the estimation of specific fluxes revealed that up to $12 \mu \mathrm{g} / \mathrm{m}^{2} / \mathrm{yr}$ (i.e. $0.9 \mathrm{t} / \mathrm{yr}$ on average) of PCBs were brought by French rivers, especially by the Rhône, Seine and Loire Rivers (ranked in order of importance) to Western European seas since the 1970s. 
